\title{
Significados de eletrostática interpretados por meio da gesticulação de estudantes
}

\author{
Meanings of electrostatics interpreted \\ through students' gestures
}

\author{
Carlos Eduardo Laburú ${ }^{1}$. Osmar Henrique Moura da Silva ${ }^{1}$ • \\ Andreia de Freitas Zômpero ${ }^{2}$
}

\begin{abstract}
Resumo: Os multimodos e múltiplas representações têm sido uma das referências das investigações em educação científica e matemática. Seu objetivo é pesquisar diversificadas formas e modos representacionais, tendo em vista aprendizagens com maior significação. Uma linha de investigação estuda os diferentes papéis da representação gestual durante o discurso científico em sala de aula. Com a intenção de avançar nessa linha de investigação, este trabalho volta-se para a observação da gesticulação de estudantes. A gesticulação em estudo será aquela realizada por estudantes, atuando em atividades empíricas. O trabalho defende que a gesticulação de estudantes nas tarefas experimentais é um modo representacional auxiliar que pode ajudar a revelar os significados do que se está aprendendo. Com esse intuito e fazendo uso da metodologia de estudo de caso, um estudante de Ensino Médio tem suas gesticulações analisadas em uma atividade experimental de física com a finalidade de conhecer seu entendimento dos conceitos científicos ensinados.
\end{abstract}

Palavras-chave: Gesticulação. Eletrostática. Significação. Ensino de física.

\begin{abstract}
Multimode and multiple representations have been one of the topics of investigations in science and maths education. The goal is to find more diverse representational forms and modes in order to make learning more significance. One line of study examines the different roles of auxiliary gestural representation during the scientific discourse in the classroom. Continuing this line of research, this paper observes the gestures of students. The gesticulation studied is among students working on empirical activities. The paper argues that the gestures of students performing experimental tasks are an auxiliary representational mode that can help to reveal the meaning of what they are building. With this aim in mind, and using the case study methodology, a high school student has his gesticulations analysed in an activity in experimental physics with a view to ascertaining his understanding of the scientific concepts taught.
\end{abstract}

Keywords: Gesticulation. Semiotics. Electrostatics. Physics teaching

\footnotetext{
${ }^{1}$ Departamento de Física, Universidade Estadual de Londrina (UEL), caixa postal 6001, CEP 86051-970, Londrina, PR, Brasil. E-mail: laburu@uel.br

${ }^{2}$ Universidade Norte do Paraná, Londrina, PR, Brasil.
} 


\section{Introdução}

A apropriação dos conhecimentos científicos na escola costuma, prioritariamente, se fazer na forma verbal oral e escrita. Todavia, especialmente na instrução de jovens, trabalhos como de Kim, Roth e Thom (2011) sugerem, aos educadores científicos, que a imagem convencional estática e abstrata de ensinar e aprender ciências, presa na exclusividade da representação verbal, precisa ser repensada. Com o objetivo de superar tal inquietação, coloca-se a perspectiva do programa de pesquisa em ensino de ciências que valoriza o uso variado e integrado de múltiplas linguagens e modos representacionais (LEMKE, 2003; PRAIN; WALDRIP, 2006). Derivada desse programa, uma linha de investigação reconhece que a imersão dos estudantes nos conhecimentos científicos passa pela atuação gestual e, por essa razão, desenvolve estudos para entender e explorar a importância dos gestos para o ensino e aprendizagem.

A linha de investigação em representação gestual considera essa componente representacional, entre outras, essencial para assistir a apreensão dos conteúdos científicos dos estudantes. De maneira semelhante às representações semióticas (DUVAL, 2004) em forma de palavras ou de registros matemáticos, os gestos expressam ideias, ainda que, nem sempre, emitidos intencionalmente como instrumento simbólico de comunicação ou possuindo o potencial de expressar ideias semelhantes aos outros dois mecanismos de representação. Ademais, como se verá em detalhes, as pesquisas nesse campo indicam que os gestos não se caracterizam apenas por sua natureza complementar de produção e troca de sentidos, mas de apoio e ajuda para que as primeiras ideias dos abstratos conceitos científicos dos estudantes comecem a ser construídas.

Originárias de uma tradição de estudos do corpo (GUIRAUD, 2001), as pesquisas correntes em educação científica, ao investigarem a influência dos gestos de professores e estudantes em sala de aula, tendem a enfatizar o gesto súbito produzido por eles em momentos instrucionais. Por ser o gesto um signo, a questão colocada pelas pesquisas é estabelecer que significado o mesmo transmite e quais consequências de interesse educacional podem advir disso. Comparecendo como papel auxiliar e complementar do discurso protagonizado por um emissor (professor ou aluno), os gestos apresentam variadas funções de indicação, e, devido às suas presenças concatenadas ao contexto discursivo, são úteis para interpretá-lo. No entanto, em ambientes em que a atuação empírica se mostra necessária, como em salas de laboratórios didáticos, por exemplo, onde ações sobre artefatos, objetos e manipulação de instrumentação científica e experimentos se fazem presentes, os gestos instantâneos, por se constituírem subunidades das ações, veem-se limitados na maneira pela qual podem ser utilizados junto às pesquisas.

Tendo isso em vista e em contraponto às pesquisas em andamento, este trabalho pretende avançar na questão dos gestos, estendendo-os à gesticulação no ensino das ciências. Por gesticulação, estaremos entendendo como "gestos em ação", ou seja, a ocorrência temporal de uma sequência de gestos instantâneos que se encadeiam, formando e completando uma ação sobre o ambiente empírico. Tal qual o gesto, veremos que uma ação ou gesticulação tem, por detrás, um significado, pois o protagonista da ação, ao realizá-la, tem em mente uma finalidade concebida que o levou a resolver ou a tentar resolver um problema de interesse prático. Por conseguinte, o foco deste estudo ultrapassa o gesto estático, isolado, e se concentra em perscrutar a ação de estudantes sobre objetos, artefatos e instrumentação científica que se concatenam em arranjos experimentais empregados para ensinar as ciências da natureza. 
Este estudo de caso mostra a viabilidade da observação das gesticulações como mecanismo auxiliar para interpretar os significados apropriados de um conceito de física ensinado. Para isso e por razão de limites de espaço, um estudante do Ensino Médio é solicitado a aplicar o que aprendeu verbalmente em uma situação real. Antes, porém, dessa apresentação, situaremos as pesquisas sobre o tema, aprofundando sua problemática e relevância para a área.

\section{Fundamentação teórica}

As reflexões a seguir, trafegarão pelos seguintes assuntos: gestos e formação cognitiva; gestos na investigação da educação científica e matemática; gesticulação sobre o mundo empírico como entidade semiótica de representação. Não obstante a tentativa de manter o desenvolvimento dos assuntos em subseções isoladas, o entrelaçamento íntimo entre os mesmos torna tal empreendimento pouco factível, o que faz com que uma subseção, em parte, venha a se refletir sobre a outra.

\section{Gestos e cognição}

A representação gestual é uma linha de investigação pertencente ao programa mais geral de pesquisa em multimodos e múltiplas representações. A tese central desse programa baseia-se no fundamento semiótico de que os signos não funcionam de maneira idêntica cognitivamente e nem proveem de um sistema de representação único (BENVENISTE, 1974 apud DUVAL, 2004, p. 66). Isto porque toda representação é cognitivamente singular em relação ao que representa, sendo mais ou menos fácil de realizar em um sistema semiótico do que em outros, além de não apresentar uma forma exatamente semelhante de ver e apreender um mesmo conteúdo conceitual (DUVAL, 2006), caso contrário, suas alternativas seriam logicamente supérfluas e dispensáveis. Consequentemente, cada sistema semiótico nos permite e remete a uma maneira distinta de significar e pensar, sem que haja redundância (RADFORD; BARDINI; SABENA, 2007). Desta forma, a confluência, o revezamento e o cruzamento de múltiplas representações apuram, restringem e refinam a produção do significado de um conceito, complementando e integrando suas várias perspectivas.

A implicação cognitiva referente ao modo de representação gestual viu-se reforçada e motivada por distintos campos de pesquisa. Estudos a respeito da formação da linguagem indicam que a mobilização do pensar na comunicação gestual parece não equivaler à mobilização da comunicação vocal, uma vez que a organização mental dos gestos é diferente daquela da vocalização. Resultados apontam (CORBALLIS, 1999) que a origem da linguagem humana pode estar nos gestos humanos, e não na vocalização. Para reforçar essa conclusão, é possível constatar que o controle cerebral dos gestos em crianças é muito anterior ao da vocalização. Um bebê humano controla os gestos bem antes de pronunciar qualquer palavra. Piaget (1982) observou que a inteligência prática inicia-se em estágio pré-verbal nos bebês, sendo ela sensóriomotora, baseada em ações e percepções. Somente a partir de um ano e meio, aproximadamente, a criança passa a um estágio de desenvolvimento da inteligência baseado nas representações em que a construção da linguagem se inicia. 
Nessa questão, parece haver um paralelismo entre a psicogênese e a ontogênese. Ora, em relação a isto, está-se chegando à conclusão de que, na evolução humana, o sistema gestual teve papel crucial para conduzir à linguagem (ORIGINS..., 2008). No hemisfério esquerdo do cérebro, são encontradas as áreas de Broca e Wernicke, responsáveis pela produção da linguagem e compreensão, respectivamente. Ambas trabalham juntas, via um corredor neural que as conecta, permitindo que entendamos o que ouvimos. Entretanto, a linguagem de sinais deve possuir uma primitiva, indelével e específica importância, pois as duas áreas são ativadas pela gesticulação pantomímica, possibilitando entender o movimento de um sinal e interpretá-lo. Tal ocorrência tem sido interpretada como base evolucionária da compreensão dos sons de uma linguagem (ORIGINS..., 2008). Assim, a linguagem desenvolvida a partir dos gestos tornou possível sua codificação. Seu significado, sua interpretação, formulação e transmissão acabaram por formar um núcleo comum durante a evolução humana.

No campo da semiótica, a implicação dos multimodos de representação para a atividade de pensamento e a apropriação dos significados passa por várias perspectivas teóricas que se esforçam por entender a dinâmica entre gesto e verbalização. Alguns autores creem que o primeiro apenas serve para facilitar o último. Outros imaginam que ele tem uma função substitutiva para um item léxico temporariamente inacessível. Há os que defendem que, em vez de reforçar a mensagem verbal, o não verbal participa, muitas vezes, de maneira incontrolada, inconsciente e não intencional, inclusive, estando em contradição com o conteúdo proposto pela fala articulada (SANTAELLA; NÖTH, 2004). Há, ainda, aqueles que defendem que os gestos e a fala são partes da mesma fonte cognitiva, sendo capazes de revelar aspectos do conteúdo mental ao mostrar os pensamentos internos e maneiras de entender os eventos do mundo do falante, assim, funcionariam como janelas para acessar o pensamento (RADFORD, 2009). Algumas dessas perspectivas pertencem a uma longa tradição estabelecida que olha o pensamento como atividade puramente mental, algo imaterial, impalpável, que ocorre independente do corpo e atua só na cabeça. Um ponto de vista diferente deste compreende que a atividade mental não consegue prescindir da coordenação da fala, corpo, gestos, símbolos e ações sobre as ferramentas e o meio. Segue daí que qualquer atividade corpórea tem relevância cognitiva, e, como para Roth e Lawless (2002), os gestos são um profundo traço da cognição, eles não podem ser dissociados da proeza intelectual que acompanha os indivíduos.

Particularmente, então, em havendo algum elemento que possa vir a auxiliar a iluminar a intricada construção do pensamento científico e matemático dos estudantes e dar profundidade aos seus conhecimentos, este deve ser buscado em gestos, olhares, ações e outras produções semióticas, e não apenas em testes, questões e avaliação escrita padrão (O’BYRNE, 2009). Sem desvalorizar o papel destas últimas e dos símbolos escritos normalmente vinculados a elas, a ideia de que a cognição científica e matemática não despreza outros tipos mediadores de signos deixa de ser problemática.

Segundo Gehlen (1988 apud RADFORD, 2009, p. 114), o ato de conhecer só pode ser assegurado por meio de uma experiência multissensorial do mundo e por apreensão autossensorial das coisas, consequentemente, decorre que os indivíduos são seres em ação. A plasticidade e colaboração dos múltiplos sentidos humanos contribuem para essa apreensão. A compreensão inicial mais completa de um objeto como uma vara, por exemplo, passa pela avaliação visual de seu comprimento, mas sua rigidez ou peso só podem ser abstraídos por meio de uma experiência tátil, contando pouco o visual. Quando os estudantes se engajam em 
conversações na presença de objetos materiais, estes proveem uma base fenomenológica frente a qual os sujeitos podem encenar gestos metafóricos que dão corpo às abstratas entidades conceituais (ROTH; LAWLESS, 2002).

As afirmações de que a fala e o gesto são elementos de um único e integrado processo cognitivo de formação da expressão é decorrência de propriedades singulares de pensamento de cada um. Enquanto a fala é composta de segmentos que são produzidos segundo uma temporalidade linear e que precisam ser estruturados segundo uma hierarquia analítica possível de ser decomposta, o gesto tem seu significado proveniente de um todo fixo e momentâneo. Ele resulta de uma imaginação instantânea, sinteticamente global, não sendo decomposto em partes separadas (RADFORD; EDWARDS; ARZARELLO, 2009). Por contraste, a pantomima, a cinética da ação corporal ou do modo fílmico, em razão das próprias dinâmicas cronológicas gestuais ou figurativas envolvidas, têm, nesse aspecto particular, aproximação com a fala ou a leitura. Contrastante ainda com o gesto, uma figura joga um papel heurístico ao permitir trabalhar numa dimensão superior à das unidades figurais que representam (DUVAL, 2004). As figuras ou os esquemas possuem o mérito de representar a totalidade instantânea das relações entre os elementos que constituem um objeto ou uma situação. Ambos possibilitam modificações visuais surgidas das relações das partes com o todo e que podem ser realizadas mentalmente ou fisicamente independentes de qualquer conhecimento específico.

Diferentemente do signo verbal, os gestos, as ações manipulativas, as imagens visuais, a textura, o paladar, o cheiro são signos analógicos, visto serem capazes de envolver uma relação de graduação contínua. Eles podem significar infinitas sutilezas que vão além das palavras. Por exemplo, emoções e sentimentos são significados analógicos que não podem ser diretamente relacionados a um léxico de dicionário ou de uma sintaxe padronizada da maneira semelhante ao signo linguístico. Os códigos analógicos são capazes de nos deixar levar, revelando atitudes, disposição, intenção e veracidade entre outras coisas. A qualidade analógica gradual desses códigos, ao mesmo tempo em que se mostra pobres em precisão e complexidade sintática, pode, por oposição, enriquecer o significado do que está sendo pensado (CHANDLER, 1994). Em Prain e Waldrip (2006) e Lemke (2003), se emprega o termo topológico para esses tipos de signos. De natureza diversa dos signos verbais tipológicos, ricos para expressarem raciocínios semânticos, qualificarem ideias ou realizarem contrastes e relações entre categorias, os topológicos são apropriados para expressarem significados quantitativos, de intensidade ou de grau.

Em razão da aparente posição empirista de Gehlen (1988 apud RADFORD, 2009, p. 114) acima, é preciso esclarecer que a mesma não propõe derivar a consciência, a imaginação e a linguagem do processo corporal. O que Gehlen afirma, assim como fazem os defensores do programa de múltiplas representações, é que o pensamento, a imaginação e a representação repousam sobre uma larga base de funções sensoriais expressas por meio das mãos, olhos e linguagem. Seria uma simplificação indevida tentar atribuir como causa da linguagem os meios sensoriais, ou afirmar que aquela evolui destes, como lembra o próprio Gehlen (1988 apud RADFORD, 2009, p. 114). O problema é mais complicado do que isto, pois o meio ambiente em que os humanos vivem não é um meio ambiente "natural", mas simbólico, transformado previamente pela atividade humana (RADFORD, 2009). Embora a linguagem possa ser considerada uma extensão de um sistema de inter-relações profundas, enraizadas de movimento e sensações (GEHLEN, 1988 apud RADFORD, 2009, p. 115), ela, dificilmente, se reduz a esse sistema. De fato, o encontro com os significados historicamente construídos da ciência vai além 
do reino sensório das coisas e do sentido comum com que seus termos possam vir a ser usados na vida diária. Assim, o significado não se restringe a uma mente individual, da mesma forma que não pode ser separado do reino dos signos que são trocados entre os membros de uma comunidade. O significado é uma categoria social, só alcançado em território interindividual (KUBLI, 2005). A manifestação da linguagem se faz ontologicamente a partir da sensação e da prática comunicativa, porém é tanto subjetiva quanto social, e, por consequência, convencional.

A consequência das colocações acima é de que cada modo de representação pode ser considerado como parte da tentativa sensória do indivíduo para tratar e se apropriar das ideias abstratas da cultura produzida, ou seja, dos significados dos seus signos. O compartilhamento cognitivo decorrente disto, do qual depende a interação e a comunicação, resulta de uma multiplicidade de métodos tácitos de formas de raciocinar impregnadas nas representações. E assim como a linguagem está para o desenvolvimento do pensamento, como coloca Vygotsky, gestos e ações etc. igualmente atuam junto à verbalização para a formulação do pensamento (LABURÚ; ZÔMPERO; BARROS, 2013). Em suma, o processo simultâneo de verbalização, gesto e ação agencia, por integração mútua, o pensamento e é promotor do significado. Cada representação sígnica, ao operar com recursos mentais de eficácias intelectuais diferentes, leva ao aprofundamento da compreensão conceitual.

\section{Gestos no ensino de ciências e matemática}

A compreensão e a comunicação do discurso científico abrangem uma multiplicidade de modos e formas representacionais, tais como: a verbalização, os gráficos, as tabelas, a álgebra, os diagramas, os objetos e modelos tridimensionais, a simulação computacional etc. (PRAIN; WALDRIP, 2006). Além desses modos e formas convencionais, outros não formais podem ser explorados pelo professor em sala de aula, tendo em vista que cada representação apresenta relevância motivacional singular e função cognitiva seletiva, complementar e organizadora para apropriação, pelo aprendiz, do referido discurso. A variabilidade representacional conduzida pela atividade cognitiva de conversão (DUVAL, 2004), ou mais amplamente, de troca de modos e formas de representação, com suas exigências de transcodificação (JOLY, 2004) e coordenação de representações semióticas, é questão vital para que o discurso científico e matemático seja apropriado pelos aprendizes (SCHNOTZ, 2002). Frente a um panorama educacional de diversidade representacional, as atividades experimentais e o modo de representação da atuação corporal que as acompanham são considerados cruciais para a aprendizagem do conhecimento científico e matemático (RADFORD; EDWARDS; ARZARELLO, 2009).

Como atividades corporais, se consideram os gestos, as posturas, as expressões faciais, os comportamentos etc. Tais atividades foram estudadas nos anos quarenta para se entender a produção de organizações significativas que, combinadas, geravam outros significados mais complexos. Sob esses interesses, a Cinésica se consolida como um ramo de estudos que decodificou e sistematizou as comunicações não verbais do movimento e sinais do corpo (CORRAZE, 1982; PIMENTA, 2006; RECTOR; TRINTA, 1990).

Por sua vez, estudos mais recentes e especificamente voltados à investigação gestual na área de educação matemática e científica (ARZARELLO et al., 2009; EDWARDS, 2009; PING; GOLDIN-MEADOW, 2010; RADFORD, 2009; ROTH, 2001) vêm concentrando seus interesses no papel dessa representação para o desenvolvimento do pensamento e da comunicação do 
discurso matemático e científico. Eles sustentam que enunciados orais e escritos, em diversos momentos instrucionais, podem se tornar pouco compreensíveis na ausência de gestos. Além disso, ressaltam a relevância dos gestos para esclarecimento dos pronunciamentos emitidos pelo professor ou estudante quando comunicam informações que a verbalização omite, assim como o papel que eles têm de complemento ou de ênfase, tal qual a prosódia. Aliás, quando se trata da linguagem oral, a gestualidade, assim como as pausas, paisagens do rosto, sutilezas do olhar e posições do corpo no espaço, tudo ajuda a roteirizar as junções e disjunções da fala com aquilo sobre o que se diz (SANTAELLA, 1995). Com função de acompanhamento do discurso, o referido modo de representação permite que várias ambiguidades e más interpretações cometidas pelo professor possam ser evitadas. Particularmente, quando o ambiente de ensino comporta as atividades experimentais mencionadas, ultrapassar as limitações do modo verbal é, até mesmo, mais crucial. A explicação, pelo aluno, de um procedimento experimental praticado por ele, mediante relato oral ou escrito, restringe o julgamento do professor a respeito do compreendido pelo estudante. Neste caso, a avaliação perceptual mostra seu valor, pois, parte do que os aprendizes querem expressar, a verbalização pode deixar de transmitir (KIM; ROTH; THOM, 2011). Um ponto relevante a destacar refere-se à discrepância existente entre os gestos e o que é falado pelos estudantes mais jovens, em momentos em que estão em estado de transição de entendimento. Observam Goldin-Meadow et al. (1992, 1993 apud ROTH; LAWLESS, 2002, p. 289) que, nessa condição de transição, a competência linguística dos estudantes costuma se encontrar pouco desenvolvida para ser expressa na modalidade verbal, embora os gestos descrevam novos entendimentos. Daí que a articulação verbal e gestual integrada permite que se construa uma totalidade discursiva mais inteligível do discurso e, portanto, do que o estudante está pensando.

Considerando tais preocupações, os estudos em representação gestual investigam algumas questões significativas para a área. Por exemplo, buscam-se, na análise gestual, elementos-chave de demonstração de comunicação em sala de aula de professores ou alunos (RADFORD; EDWARDS; ARZARELLO, 2009; ROTH, 2001), e que mantenham relação com a conceituação expressa, de tal forma que se considerem fases articuladas dos movimentos gestuais (BRESSEM; LADEWIG, 2011). Em Edwards (2009), os gestos são classificados e examinados quanto à maneira de conceituar as noções matemáticas a respeito de fração empreendida pelos estudantes. Em Roth e Lawles (2002), é evidenciado que, longe de ser ociosa, a expressão corporal gestual proporciona profunda função cognitiva na emergência dos conceitos abstratos científicos dos aprendizes, pois, como indicam Kastens, Agrawal e Liben (2008), o gesto está intimamente conectado com a percepção e cognição e, assim, acarreta sutis significados que, de outra forma, seriam conduzidos de maneira inábil ou, mesmo, seriam impossíveis de vir a ser conduzidos, caso a linguagem fosse unicamente empregada. Por final, Arzarello et al. (2009), ao acompanharem essas investigações, concentram-se no relacionamento da componente gestual com a linguagem falada como diferentes lados de um sistema único de processo mental subjacente de ensinar e aprender.

\section{Gesticulação em atividades empíricas}

As pesquisas em educação científica e matemática tendem a dirigir seus estudos para os gestos de tipo dêitico, icônico ou metafórico (KENDON, 1993 apud ROTH; LAWLES, 
2002, p. 289; PICCININI; MARTINS, 2004). Diferentemente dos gestos vazios de conteúdo proposicional, com função de prover uma estrutura temporal à comunicação ou facilitar a procura por uma palavra momentaneamente em falta, os gestos discriminados têm função de apontar, encenar ou simbolizar, junto à narrativa, objetos que podem estar ou não presentes (ROTH; LAWLES, 2002).

Sobretudo no ensino das ciências naturais, as operações e manipulações aplicadas ao mundo empírico são consideradas um modo de representação a ser ressaltado dentre as múltiplas variabilidades representacionais possíveis de serem trabalhadas em sala de aula (PRAIN; WALDRIP, 2006). Além de inerentemente vinculada aos conhecimentos científicos da natureza, o que por si já justificaria a atuação sobre a realidade, a ação prática é igualmente apontada como um modo de representação fundamental para a aprendizagem das ciências (LABURÚ; SILVA, 2011). Isto advém da capacidade da representação manipulativa participar do pensar científico, na medida em que provê, sustenta, constitui, auxilia e subsidia a formação do significado das ideias científicas, juntamente com as representações formais verbais, matemáticas, entre outras. Procedimentos, condutas, gestos e encaminhamentos de ações práticas, ao tomarem parte no manejo de objetos e artefatos científicos, manuseio e composição estrutural de experimentos, subsidiam não apenas a elaboração intelectual dos conceitos científicos estudados, mas permitem expressar, por meio do ato, ou, mais propriamente, da gesticulação que o acompanha, o que está sendo compreendido, ainda que palavras não sejam pronunciadas. Apoiando esse entendimento, Roth e Welzel (2000) manifestam que os gestos contidos na manipulação de materiais concretos no laboratório jogam um papel acessório e colaborativo para a constituição do discurso científico, adiantando-se a ele quando os aprendizes ainda mostram pouco domínio a respeito do assunto.

Tais alegações têm, no referencial semiótico, a seguinte justificativa. Por ele, o mundo material é um signo tanto quanto um símbolo qualquer. De fato, a realidade dos fenômenos e do signo se mistura. Lembra Peirce (1992) que o mundo não é feito de coisas de um lado e signos de outro, como se as coisas fossem materiais e as linguagens imateriais. Para ele, todo signo encontra-se encarnado em alguma espécie de coisa, ou seja, qualquer signo é também fenômeno; algo que aparece à nossa mente. Toda coisa material é, então, um signo, uma impressão que associamos a outra coisa. A única particularidade desse e outros signos não verbais, comparada com o signo linguístico, é que este último produz associações de ideias mais precisas e de forma mais perfeita do que os anteriores, uma vez que ele pertence a um código preestabelecido e relativamente fechado. Logo, as coisas podem funcionar como signos, sem que deixem de ser coisas. Agir como signos, como representação, é um aspecto das coisas, dos fenômenos (SANTAELLA; NÖTH, 2004). Efetivamente, mesmo um signo strito sensu possui uma materialidade que percebemos com um ou vários sentidos, sendo, portanto, possível vê-lo, senti-lo, ouvi-lo, tocá-lo ou, ainda, saboreá-lo (JOLY, 2004, p. 32). Ora, toda vez que pensamos, como afirma Peirce (1992 apud ECO, 2003, p. 146), temos presente na consciência algum sentimento, imagem, concepção ou outra representação que serve de signo. A perspectiva semiótica peirceana leva a noção de representação sígnica tão longe que a mesma não precisa ter plena natureza de uma linguagem, mas pode estar expressa em uma mera ação ou reação (por exemplo, correr para alcançar alguém), uma simples emoção ou qualquer sentimento como, por exemplo, a qualidade vaga de sentir ternura, desejo, raiva, dor etc. Por conseguinte, ao serem externadas, emoções, ações e reações, entre outras experiências, dão corpo aos pensamentos (SANTAELLA, 2005), produzem e transmitem significados. 
Radford (2012) complementa essas posições, esclarecendo que qualquer artefato é carregado de significado social e histórico, afirmação extensível para os experimentos científicos e atividades empíricas no sentido amplo. Mas, para que se cumpram as funções para as quais foram criadas, ações específicas, com suas respectivas gesticulações, devem ser realizadas com fins culturais particulares, pois, fora desses fins, os artefatos e atividades empíricas perdem a atribuição para a qual foram elaborados. Consequentemente, já que ações e gesticulações se veem intimamente ligadas com a concretização de uma representação mental (DUVAL, 2004), por meio da manipulação de artefatos e instrumentos culturais, elas não deixam de ser consideradas entidades simbólicas. A posição do autor é impregnada da concepção vygotskiana, haja vista que esta última entende que, no fluxo do pensamento, nem a mão nem o intelecto prevalecem por si sós, mas se veem modelados pelos instrumentos e ferramentas da linguagem construída pelo ser humano, que os usa para o desenvolvimento da sua linguagem interiorizada e pensamento conceitual. De acordo com Vygotsky (2003), o pensamento consegue funcionar sem quaisquer imagens verbais, e se manifestar no uso de instrumentos, da mesma forma que o intelecto prático em geral.

As posturas semióticas e psicológicas expostas concordam com a visão epistemológica de que toda observação - termo carregado de um sentido empírico - é realizada à luz de uma teoria. O que importa destacar deste aforismo popperiano (POPPER, 1993) é a inexistência de ações em uma mente vazia. Portanto, o jogo entre o fazer e o compreender ou entre o manipular e o aprender torna-se íntimo e indissociável. Influenciando um ao outro, eles algumas vezes caminham paralelamente, outras vezes fundem-se, como seria desejável.

As leituras precedentes estão presentes e são reforçadas pelo referencial em multimodos e múltiplas representações da educação científica. Por ele, estimular mudanças representacionais como mecanismo de consolidação da aprendizagem em ciências significa empregar igualmente o modo representacional das ações proporcionado pelas práticas experimentais, como autênticas trocas ou passagens de representação da linguagem verbal e matemática para a visual/manual. A nosso ver, a transcodificação do verbal e matemático para o visual vinculado ao fazer, ao manusear, é semioticamente isomorfa do que Joly (2004, p. 73) chama de "materialização do equivalente visual do falado ou escrito". Segundo a autora, nada há de absurdo nisso, visto ser tal ocorrência comum na publicidade no momento em que se deseja evocar determinados conceitos como, por exemplo, de juventude ou liberdade em um projeto visual. Para o que queremos apontar, isto se traduz na materialização dos abstratos conceitos científicos em ação, em procedimento concreto, objetivando o aprofundamento conceitual e a aprendizagem com significado.

Ainda que gestos e ações possam ter seus sentidos confundidos e não exista maior preocupação em separá-los nos estudos da área, apesar do cuidado que alguns têm, ao menos, em separá-los formalmente (RADFORD, 2009; ROTH; LAWLES, 2002), é preciso advertir que, na perspectiva discutida aqui, eles encerram uma nítida distinção conceitual e metodológica. Devido ao foco de esta investigação se voltar para as atividades empíricas, o que não ocorre com a maioria dos trabalhos nessa linha de investigação, a exceção de Roth (2004) e Roth e Welzel (2000), as ações, para nós, têm maior importância do que os gestos. Estes últimos, devido a sua instantaneidade, abandonam o modo de representação no tempo. Percebamos que, em uma só imagem ou ocorrência gestual instantânea, é impossível contar uma história, enquanto pela gesticulação de uma imagem em sequência ou animação proporciona-se um meio para 
que se constituam narrativas com relações temporais e causais. Trabalhos que têm os gestos como objetos de estudo, pela própria limitação dessa representação, servem-se frequentemente das referidas relações para contextualizar o significado de um gesto instantâneo e isolado, sem as quais sua interpretação seria pouco confiante. Entretanto, as ações podem ser pensadas como uma composição temporal de gestos fragmentados que se interligam e dirigem para um determinado fim. Logo, uma combinação de gestos em ação, ou, simplesmente, gesticulação, culmina, no limite, em atos que se aproximam da pantomima. Entretanto, diferentemente desta última, a gesticulação antes de ser comunicativa é expressiva em primeiro lugar (ECO, 1985), o que significa dizer que seus signos costumam ser não intencionais na relação emitente e destinatário. Assim, a gesticulação se apresenta, basicamente, como um ato de autorreflexão e de pensamento em ação do emissor sem que os signos expressos por ele sejam direcionados necessariamente para um receptor.

Afora o observado no parágrafo anterior, as reflexões a respeito dos gestos podem ser diretamente estendidas para a gesticulação. Como dito, esta compõe uma linguagem corporal de natureza representacional. Do ponto de vista da importância pedagógica e baseada nas considerações precedentes, a gesticulação sintetiza duas dimensões a serem atendidas: uma, cognitiva, haja vista seu papel auxiliar na construção do pensamento e elaboração do significado do aprendiz do que está sendo estudado. Outra, de interesse deste trabalho, de natureza avaliativa processual, visto se constituir em uma linguagem que permite, ao professor, apreciar o significado do conhecimento do que está sendo construído pelo estudante.

Considerando este último ponto, na continuidade, é mostrado o potencial da gesticulação como modo de representação capaz de caracterizar o significado conceitual que o estudante está construindo no momento em que o conteúdo estudado vem sendo aplicado experimentalmente no laboratório didático.

\section{Metodologia}

A decifração do significado dos gestos e ações de um sujeito possui menor objetividade do que sua linguagem verbal poderia vir a informar. Logo, interpretar a gesticulação de um estudante não consiste em uma empreitada precisa para quem interpreta, por isso, tentar encontrar o máximo significado que ela possa transmitir é um desafio. Para tal empreitada são necessários pontos de referências para a análise que consistem em conhecer as circunstâncias, o contexto e o que se pretende com a gesticulação de um ato para atingir um determinado objetivo. No caso deste trabalho, as circunstâncias mantêm relação direta com as peculiaridades da situação da atividade de ensino abarcada, tais como: o ambiente empírico, os artefatos específicos utilizados para realizar a atividade, os atores envolvidos, o problema científico a atingir e as técnicas utilizadas. O contexto é aquele relacionado ao conteúdo de eletrostática em que as circunstâncias se veem postas. Porém, dado que a característica das análises desse tipo de representação tem grau de aproximação elevado, posto depender do ponto de vista do analista, a sua objetividade foi capaz de ser maximizada quando a liberdade do analista permaneceu na obrigação de compartilhar e comparar, ao máximo, suas interpretações com as de outros analistas independentes. Assim, com pontos de vistas comuns de uma análise coletiva, permitiu-se constituir limites razoáveis e verificáveis da interpretação do significado da ação 
ou gesticulação de um estudante, ou seja, o que pretendeu com o ato. Portanto, a interpretação das gesticulações apresentadas foi produto do cruzamento de três análises independentes de especialistas no conteúdo tratado.

O registro da gesticulação deu-se por meio de videogravação de sete estudantes do terceiro ano do Ensino Médio de uma escola pública, pertencentes a uma população de perfil urbano e, predominantemente, de classe média. Da amostra de estudantes, um foi selecionado para análise, tendo em vista melhor evidenciar os aspectos pretendidos e demonstrar as dificuldades e lacunas de aprendizagem. A análise faz referência a um pequeno trecho de dez minutos do registro fílmico do estudante e que está exposto na Figura 1 na forma de frames (quadro a quadro). Dada a limitação de espaço, os frames não mantêm intervalos de tempo fixos e somente instantâneos mais representativos estão apresentados, sem que se perca o significado da ação global. Os frames foram convertidos em desenhos para preservar o anonimato do participante.

No momento da filmagem, os estudantes se encontravam em uma aula de laboratório, aplicando os processos de eletrização por contato e indução em dois cilindros, para a obtenção de um dipolo elétrico, com o objetivo de mapear a configuração do campo elétrico. Como pode ser visto nos desenhos da seção seguinte e com a finalidade de deixar mais clara a compreensão das análises e sua possível reprodução, passamos à descrição e à operacionalização do material utilizado, que se constituiu dos seguintes artefatos: canudinhos de refresco que se eletrizam quando atritados com papel toalha e que servem de fontes de cargas elétricas; dois cilindros de cartolina de $(\sim 12 \times 3) \mathrm{cm}$, pintados com spray de cor metálica, sustentados por suportes de canudinhos, que são materiais isolantes; uma seta-vetor ( $3 \mathrm{~cm}$ de comprimento) eletrizada por contato com um canudinho eletrizado, feita de papel metálico usado na cozinha para embrulhar alimentos, e que servia para representar o vetor campo elétrico. A seta-vetor, equilibrada horizontalmente, permanecia pendurada por um fio de nylon finíssimo retirado de meia de nylon feminina ( $\sim 10 \mathrm{~cm}$ de comprimento) que se prendia a um suporte isolante constituído, também, de canudinhos de refresco. Um cilindro foi eletrizado pelo processo de indução e o outro por contato para simular um dipolo elétrico quando estivessem colateralmente próximos. O professor apresentou as técnicas de eletrização conjuntamente com o modelo elétrico. Para eletrizar o cilindro por contato, o canudinho eletrizado deveria ser raspado em sua máxima extensão em qualquer ponto do corpo do cilindro para que houvesse transferência de cargas do canudinho para o cilindro. Após cada operação de raspagem, o canudinho deveria ser novamente eletrizado por atrito. Tal procedimento precisaria ser feito duas ou três vezes. A técnica de eletrização pelo processo de indução do outro cilindro deveria ser conduzida com o canudinho eletrizado em posição paralela ao cilindro, em que ambos são mantidos próximos e sem se tocarem. Isso permite a máxima indução das cargas no cilindro. Em seguida, com um breve toque no cilindro com um dedo, para proceder ao seu aterramento, faz-se com que as cargas induzidas no cilindro, semelhantes ao do canudinho indutor, sejam neutralizadas. A eletrização da seta-vetor, devido a sua baixa capacitância, faz-se apenas com um toque instantâneo do canudinho eletrizado. Com os cilindros próximos um do outro e com a seta-vetor eletrizada e posicionada em vários pontos do espaço ao redor dos cilindros eletrizados, mas sem tocá-los, obtém-se a direção e o sentido do campo elétrico. Com isso, se consegue mapear a conformação das linhas do campo elétrico, que são tangentes às setas-vetor, em todo o espaço em torno dos cilindros. Ao ser vista por cima, a configuração se assemelha à de um campo de dipolo elétrico de cargas pontuais. 


\section{Resultados e discussões}

Descrição geral da gesticulação: Inicialmente, o estudante realiza o processo de eletrização por atrito, efetuando a fricção do papel toalha ao longo do canudinho, conforme indicado no frame 1 (Figura 1). Nos frames 2 e 3, ocorre o processo de eletrização por contato do cilindro à direita do estudante. A eletrização é obtida esfregando toda a extensão do corpo eletrizado do canudinho sobre um ponto do cilindro. Por meio de nova eletrização por atrito do canudinho (frames omitidos), segue-se a eletrização por indução do cilindro à esquerda do estudante (frames 4 e 5). Tendo mais uma vez eletrizado o canudinho por atrito (frames omitidos), o frame 6 mostra o estudante eletrizando a seta-vetor por contato, que se repele após o toque com canudinho (frames omitidos). Nos frames 7 e 8, o estudante executa ações para mapear a configuração do campo elétrico.

Interpretação dos Significados: As observações das gesticulações indicam que as eletrizações por atrito do canudinho foram realizadas corretamente. O mesmo pode ser dito em relação aos procedimentos referentes às eletrizações por contato e indução dos cilindros e ao processo de eletrização por contato da seta-vetor. Todavia, o procedimento para mapear o campo elétrico do par de cilindros mostra-se problemático, como faz ver o posicionamento da seta-vetor entre os cilindros eletrizados. Na gesticulação expressa nos frames 7 e 8 , o estudante coloca a seta-vetor entre os cilindros, porém abaixo dos mesmos. Nesse local, primeiramente, ele investiga manualmente o campo com a seta-vetor, posicionando-a em vários pontos (frame 7). Na sequência, deixa a seta-vetor solta (frame 8), sem ajustá-la para o meio da altura dos cilindros; ação que poderia ser efetuada suspendendo a sua haste horizontal. Tais procedimentos, todos incorretos, também ocorreram para outras posições em torno de cada cilindro (frames omitidos). Por ambos os frames 7 e 8 (e mais os omitidos), há, sem dúvida, evidências de que o significado para o estudante da distribuição das cargas e a sua vinculação com o campo nos cilindros é problemática. Consequentemente, existe falha na compreensão do motivo da necessidade de mapear o campo na região a meia altura dos cilindros, visto a mesma não sofrer efeitos de bordas e distorções; ponto que parece não ter sido devidamente interiorizado pelo estudante quando das observações do professor sobre esse problema. Assim, ele não compreende que o campo de dipolo somente é bem caracterizado na região intermediária do corpo dos cilindros, pois muito fora dela surgem distorções decorrentes de efeitos de bordas ou, simplesmente, o campo elétrico inexiste devido à ausência de carga elétrica. Esta última razão é mais preocupante, pois pode tanto indicar um modelo de distribuição de cargas e campo elétrico equivocado quanto exibir falta de entendimento do papel desempenhado pelos canudinhos abaixo dos cilindros. Estes últimos têm função meramente de suportes isolantes e sustentadores dos cilindros, além de estarem neutros no que se refere às cargas elétricas, o que, por decorrência imediata, não deveria levar a busca de campo elétrico nessa região, pois o mesmo é nulo nesse local, a menos, como dito, de fracos efeitos residuais de bordas, dependendo da posição observada. A consideração da falta de carga elétrica e sua implicação com um campo nulo é básica e esperar-se-ia que, ao menos, essa consideração fosse de domínio conceitual do estudante, porém, a análise das gesticulações nega esse entendimento. 
Figura 1. Frames da gesticulação

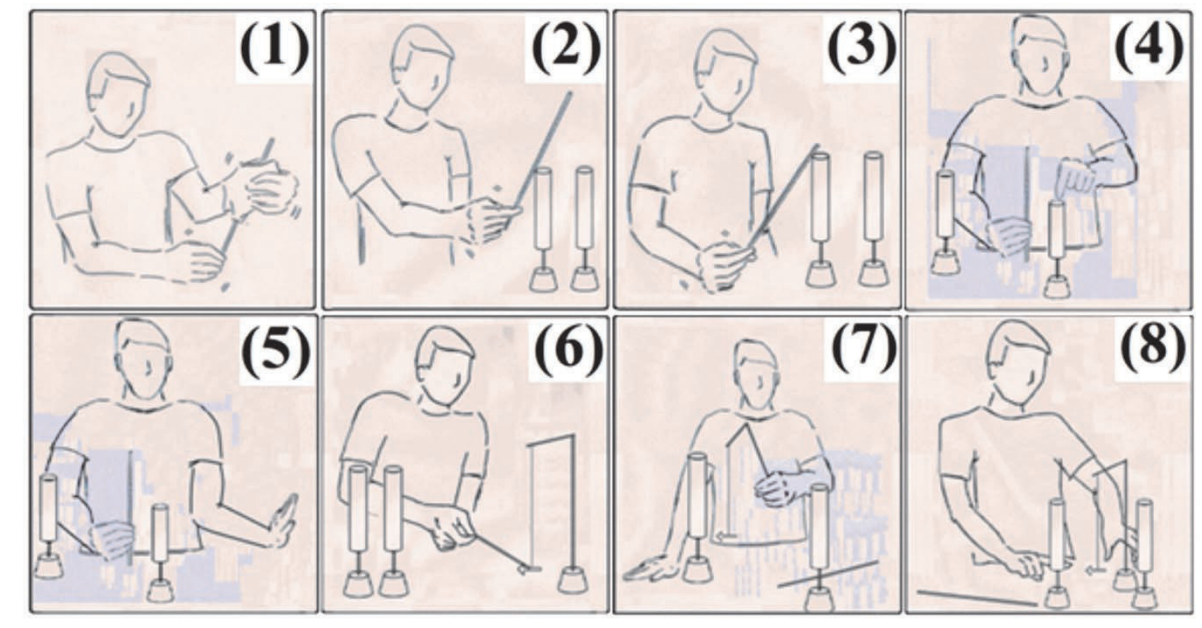

Fonte: elaborada pelos autores.

Ademais, deve-se salientar que a gesticulação, mesmo quando corretamente executada, não é garantia de que o estudante tenha se apropriado do modelo físico de maneira cientificamente esperada. Por exemplo, por trás dos procedimentos corretos de eletrização vistos nos frames 1 a 6 , de correr todo o corpo do canudinho isolante sobre um local dos cilindros condutores, não existe certeza de que tenha havido compreensão da diferenciação entre condutores e isolantes. Segundo a perspectiva da Comunicação de Buyssens (1967 apud SANTAELHA; NÖTH, 2004, p. 95), as ações de comunicar podem se apresentar como signos icônicos, posto virem tomadas pelo princípio da imitação, ou seja, da simulação, da repetição mecânica. Na hipótese desse entendimento se aplicar ao estudante, não haveria, no exemplo mencionado, uma situação acordada entre professor e aprendiz cuja base remetesse ao convencionalismo científico. Em outras palavras, as ações do estudante não expressariam signos simbólicos científicos culturamente apropriados, mas signos icônicos, produtos de mera cópia das ações do professor. Assim, procedimentos, técnicas ou destrezas experimentais válidas podem permanecer exclusivamente no âmbito do automatismo, da mera reprodução, sem que, por detrás das mesmas, necessariamente, haja um adequado significado aprendido do que esteja ocorrendo. Inversamente, é preciso que se diga, também, que o desconhecimento ou emprego impróprio de técnicas, procedimentos ou falta de destreza - todos fundamentais para a execução dos efeitos esperados de um experimento, sem os quais os resultados não são produzidos a contento - não significa que o estudante tenha uma interpretação equivocada. No caso, pode ocorrer que a conceituação do aprendiz esteja cientificamente correta, mas que a inapropriada gesticulação observada, que levaria a uma interpretação equivocada do significado apropriado pelo aprendiz, venha da simples dificuldade ou desconhecimento da operacionalização ou manipulação de instrumentos e técnicas. Isto, por exemplo, ocorreu com outro estudante observado ${ }^{3}$. 
Ele mostrou que compreendia perfeitamente o conceito de indução, fato este constatado via modo de representação oral. Entretanto, a análise de sua gesticulação leva à conclusão de não -existência de compreensão do conceito, devido à técnica de manipulação inapropriada e que acarretava em resultado empírico inválido. Logo, pode-se dizer que o indevido conhecimento de procedimentos e habilidades técnicas, conduzindo a gesticulações incorretas, não implica, necessariamente, problemas com a conceituação.

Considerada essas ressalvas, é possível se afirmar, pelas observações das gesticulações corretas dos frames 1 a 6 , que, no quesito relativo à aprendizagem de condutores e isolantes e aos processos de eletrização por atrito, contato e indução, o estudante analisado sinaliza ter se apropriado dos conceitos associados a esses temas. Por outro lado, as gesticulações reveladas pelos frames 7 e 8 mostram existir importantes problemas com o significado do conceito de campo elétrico e sua real vinculação com a existência de carga elétrica. Tal ocorrência deveria levar a maior perscrutação do professor para entender o ponto conceitual problemático do aluno, objetivando a aprendizagem correta.

\section{Conclusões}

Este trabalho procurou mostrar a viabilidade de se prestar atenção às ações exteriorizadas pelos estudantes com a finalidade de acompanhar se os seus significados dos conceitos científicos estão sendo corretamente interiorizados. Um estudo de caso mostrou que isto é possível. Todavia, também adiantamos que, em razão da natureza imprecisa da identificação do significado por meio da modalidade da gesticulação, uma maior segurança interpretativa emitida pela visualização das ações somente se viabiliza caso o professor cruze esse modo de representação com modos verbais, figurativos etc., o que um futuro estudo precisará melhor.

Além da possibilidade de averiguar conceituações errôneas do aprendiz, a proposta igualmente aponta para uma característica própria às atividades experimentais que faz com que o modo de representação por meio da gesticulação distinga-se como um modo privilegiado, se comparado a outros modos. Pouco consideradas e frequentemente menosprezadas no ensino, durante a materialização dos conceitos científicos intermediados por atividades empíricas, manifestam-se questões de ordem técnica e operacional, sem as quais tal materialização se torna impraticável. Essas questões, ou como prefere Trumper (2003) chamá-las de arte da experimentação, dizem respeito aos procedimentos ou destrezas experimentais necessárias à manipulação envolvida na operacionalização de instrumentos, experiência em processos laboratoriais e técnicas. Apesar de periféricas no ato de compreensão conceitual, e ainda que não estejam diretamente relacionadas com ela, a arte da experimentação acaba por impedir que o conhecimento seja efetivado na prática. Isto, em outros termos, significa que um conceito só consegue ser aplicado se técnicas e procedimentos operacionais forem dominados. Sem eles, muitas vezes, os conceitos não conseguem ser "visualizados" e seu incorreto domínio ou falta dele pode, indevidamente, demonstrar ininteligibilidade conceitual, sendo que a dificuldade do aprendiz pode estar localizada nesses elementos, e não na dimensão conceitual propriamente dita.

\footnotetext{
${ }^{3}$ Caso que será tratado com maior minúcia em um próximo artigo.
} 
Enfim, a gesticulação contribui não só como instrumento para o professor perscrutar o que os estudantes estão aprendendo acerca do conhecimento científico, como fizemos ver, mas, acima de tudo, quando vinculada à atuação empírica, torna-se parte fundamental para a elaboração do pensamento desse conhecimento. No primeiro caso, o professor tem a possibilidade de redirecionar e corrigir ações didáticas, visando o melhor aprendizado do aluno. No segundo, permanece o princípio teórico maior, vinculado ao modo representacional da gesticulação: a indissociável relação entre compreender e saber fazer. Em outras palavras, isto significa que o aprofundamento da compreensão conceitual científica inclui, também, saber aplicá-los com sucesso em situações reais, ao mundo, o que, por sua vez, implica gestos em ação.

\section{Agradecimento}

Agradecemos as importantes sugestões de um dos árbitros anônimos. Carlos Eduardo Laburú agradece o apoio do CNPq.

\section{Referências}

ARZARELLO, F. et al. Gestures as semiotic resources in the mathematics classroom.

Educational Studies in Mathematics, Dordrecht, v. 70, n. 2, p. 97-109, 2009.

BRESSEM, J.; LADEWIG, S. H. Rethinking gesture phases: articulatory features of gesture movement? Semiotica, Berlin, v. 184, n. 1-4, p. 53-91, 2011.

CHANDLER, D. Semiotics for beginners. [Aberystwyth, Wales?]: Daniel Chandler, 1994. Disponível em: <http://visual-memory.co.uk/daniel/Documents/S4B/>. Acesso em : 22 mar. 2012.

CORBALLIS, M. The gestural origins of language. American Scientist, Research Triangle Park, v. 87, n. 2, 1999. Disponível em: <http://www.americanscientist.org/issues/ pub/1999/2/the-gestural-origins-of-language/1>. Acesso em: 11 ago. 2015.

CORRAZE, J. As comunicações não-verbais. Rio de Janeiro: Zahar, 1982.

DUVAL, R. A cognitive analysis of problems of comprehension in a learning of mathematics. Educational Studies in Mathematics, Dordrecht, v. 61, n. 1-2, p. 103-131, 2006.

Semiosis y pensamiento humano: registros semióticos y aprendizajes intelectuales. Santiago de Cali: Universidad del Vale, Instituto de Educación y Pedagogía, 2004.

ECO, H. O signo. Lisboa: Presença, 1985.

. Tratado geral de semiótica. São Paulo: Perspectiva, 2003. 
Laburú, C. E.; Silva, O. H. M.; Zômpero, A. F.

EDWARDS L. D. Gestures and conceptual integration in mathematical talk. Educational Studies Mathematics, Dordrecht, v. 70, n. 2, p. 127-141, 2009.

GUIRAUD, P. A linguagem do corpo. São Paulo: Ática, 2001.

JOLY, M. Introdução à análise da imagem. 7. ed. Campinas: Papirus, 2004.

KASTENS, K. A.; AGRAWAL, S.; LIBEN, L. S. Research in science education: the role of gestures in geoscience teaching and learning. Journal of Geoscience Education, Northfield, v. 56, n. 4, p. 362-368, 2008.

KIM, M.; ROTH, W-M.; THOM, J. Children's gestures and the embodied knowledge of geometry. International Journal of Science and Mathematics Education, Dordrecht, v. 9, n. 1, p. 207-238, 2011.

KUBLI, F. Science teaching as a dialogue: Bakhtin, Vygotsky and some application in the classroom. Science \& Education, Hoboken, v. 14, n. 6, p. 501-534, 2005.

LABURÚ, C. E.; SILVA, O. H. M. O laboratório didático a partir da perspectiva da multimodalidade representacional. Ciência \& Educação, Bauru, v. 17, n. 3, p. 721-734, 2011.

LABURÚ, C. E.; ZÔMPERO, A. F.; BARROS, M. A. Vygotsky e múltiplas representações: leituras convergentes para o ensino de ciências. Caderno Brasileiro de Ensino de Física, Florianópolis, v. 30, n. 1, p. 7-24, 2013.

LEMKE, J. L. Teaching all the languages of science: words, symbols, images, and actions. [2003]. Disponível em: <http://academic.brooklyn.cuny.edu/education/jlemke/ papers/barcelon.htm>. Acesso em: 1 fev. 2007.

O'BYRNE, B. Knowing more than words can say: using multimodal assessment tools to excave and construct knowledge about wolves. International Journal of Science and Mathematics Education, Dordrecht, v. 31, n. 4, p. 523-539, 2009.

ORIGINS of language. Direção: Bernard Favre. [S.l.]: Crescendo Films, 2008. (57 min.), son, color. Disponível em: <https://www.youtube.com/watch?v=cYJoXsfgenQ>. Acesso em: 12 ago. 2015.

PEIRCE, C. S. Essencial Peirce. Bloomington: Indiana University Press, 1992.

PIAGET, J. Seis estudos de psicologia. Rio de Janeiro: Forense Universitária, 1982.

PICCININI, C.; MARTINS, I. Comunicação multimodal na sala de aula de ciências: construindo sentidos com palavras e gestos. Ensaio: pesquisa em educação em ciências, Belo Horizonte, v. 6, n. 1, p. 1-14, 2004.

PIMENTA, S. M. O. O signo da receptividade: uma visão sócio-construtivista da interação. Belo Horizonte: UFMG, 2006.

PING, R.; GOLDIN-MEADOW, S. Gesturing saves cognitive resources when talking about nonpresent objects. Cognitive Science, Hoboken, v. 34, n. 4, p. 602-619, 2010.

POPPER, K. A lógica da pesquisa científica. 9. ed. São Paulo: Cultrix, 1993. 
PRAIN, V.; WALDRIP, B. An exploratory study of teachers' and students' use of multimodal representations of concepts in primary science. International Journal of Science Education, Abingdon, v. 28, n. 15, p. 1843-1866, 2006.

RADFORD, L. Reaction to part III: on the cognitive, epistemic, and ontological roles of artefacts. In: GUEUDET, G.; PEPIN, B.; TROUCHE, L. (Ed.). From test to "lived" resources. New York: Springer, 2012. p. 238-288.

. Why do gestures matter?: sensuous cognition and the palpability of mathematical meanings. Educational Studies in Mathematics, Dordrecht, v. 70, n. 2, p. 111-126, 2009.

RADFORD, L.; BARDINI, C.; SABENA, C. Perceiving the general: the multisemiotic dimension of student's algebraic activity. Journal for Research in Mathematics Education, Reston, v. 38, n. 5, p. 507-530, 2007.

RADFORD, L.; EDWARDS, L.; ARZARELLO, F. Introduction: beyond words.

Educational Studies in Mathematics, Dordrecht, v. 70, n. 2, p. 91-95, 2009.

RECTOR, M.; TRINTA, A. R. Comunicação do corpo. São Paulo: Ática, 1990.

ROTH, W.-M. Gestures: their role in teaching and learning. Review of Educational

Research, Thousand Oaks, v. 71, n. 3, p. 365-392, 2001.

Making use of gestures, the leading edge in literacy development. [2004].

Disponível em: < http://education2.uvic.ca/faculty/mroth/PREPRINTS/Literacy1.pdf>. Acesso em: 17 ago. 2012.

ROTH, W.-M.; LAWLES, D. Scientific investigations, metaphorical gestures, and the emergence of abstract scientific concepts. Learning and Instruction, Oxford, UK, v. 12, n. 3, p. 285-304, 2002.

ROTH, W.-M.; WELZEL, M. From activity to gestures and scientific language. New Orleans: National Association for Research in Science Teaching, 2000.

SANTAELLA, L. Semiótica aplicada. São Paulo: Thomson, 2005.

. A teoria geral dos signos: semiose e autogeração. São Paulo: Ática, 1995.

SANTAELHA, L.; NÖTH, W. Comunicação \& semiótica. São Paulo: Hacker Editores, 2004.

SCHNOTZ, W. Towards an integrated view of learning from text and visual displays.

Educational Psychology Review, New York, v. 14, n. 1, p. 101-120, 2002.

TRUMPER, R. The physics laboratory - a historical overview and future perspectives. Science \& Education, Hoboken, v. 12, n. 7, p. 645-670, 2003.

VYGOTSKY, L. S. Pensamento e linguagem. 2. ed. São Paulo: Martins Fontes, 2003. 